\title{
Miniature Gas Analysis System for Volatile Organic Compounds
}

\author{
U. Lehmann, A. Grisel \\ MICROSENS SA, PSE-D, 1015 Lausanne \\ ulrike.lehmann@microsens.ch, tel.: +41216939135
}

\begin{abstract}
$\mathrm{SnO}_{2}$ gas sensors are known for their high sensitivity towards volatile organic compounds (VOC) but

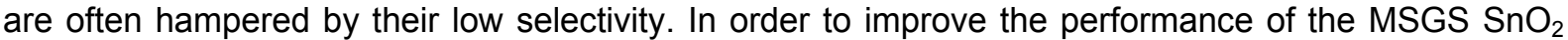
sensor it is combined with a polymer lined micro-fabricated capillary. When passing through the capillary, the components of a small sample of mixed gaseous VOCs separate and can be detected one after the other by the sensor. When combined with a suitable sample injection procedure, the detection module can be transformed into a miniature gas analysis system. In the following we will demonstrate the successful selective detection of $\mathrm{VOC}$ from mixed gaseous samples.
\end{abstract}

Keywords: Gas analysis, $\mathrm{SnO}_{2}$ gas sensor, Selective sensing, Volatile Organic Compounds (VOC)

\section{Introduction}

$\mathrm{SnO}_{2}$ gas sensors are widely used due to their high sensitivity towards volatile organic compounds (VOC) [1-2]. The high sensitivity, however, is offset by a low selectivity, making it necessary to pre-treat multi-components gas samples, most commonly via the use of a specialized filter [3]. As a consequence $\mathrm{SnO}_{2}$ gas sensors often only measure one chosen compound or the combination of gaseous compounds. In order to profit from the high sensitivity of a $\mathrm{SnO}_{2}$ gas sensor as well as its wide detection range, the components of a mixed gas sample need to arrive at the sensor separately. This can be achieved by passing a small sample volume through a capillary, a principle known from gas chromatography [4-5]. While standard gas chromatography requires a long capillary $(>20 \mathrm{~m})$, elevated capillary temperatures $\left(>200^{\circ} \mathrm{C}\right)$ and high pressures (MPa range), we present a solution that works with a comparatively short capillary $(1-2 m)$, moderate capillary temperatures (Room temperature to $\left.50^{\circ} \mathrm{C}\right)$ and low pressures $(\mathrm{kPa}$ range), with the goal to obtain a portable system.
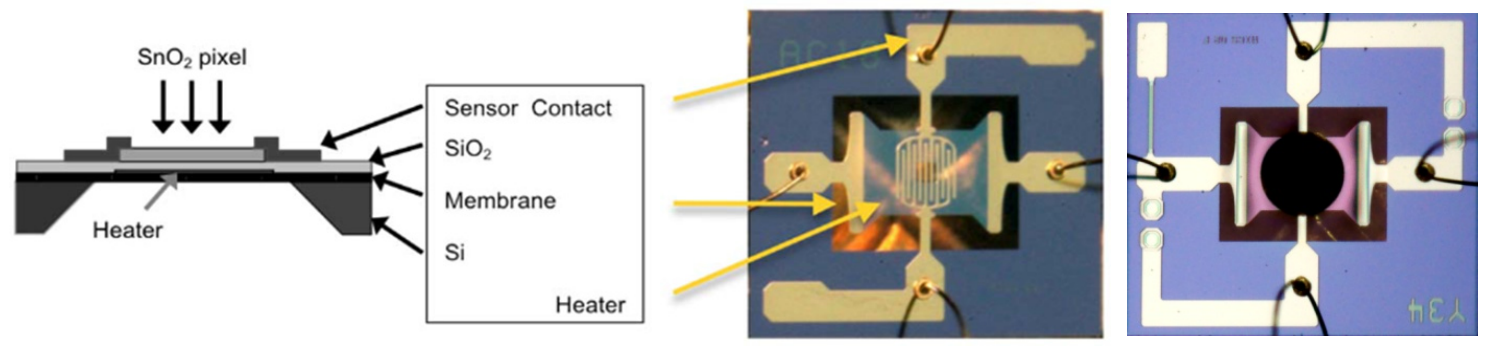

Fig. 1: The MSGS $\mathrm{SnO}_{2}$ gas sensor (Schematics and photographs).

\section{Setup and Experiments}

The proposed gas analysis system comprises of a MSGS (MICROSENS Semiconductor Gas Sensor) type $\mathrm{SnO}_{2}$ gas sensor (Figure 1) [7] and a micro-fabricated capillary in the form of a $25 \mathrm{~mm}$ by $25 \mathrm{~mm}$ large Silicon chip with glass cover (Figure 2). The internal walls of the capillary are coated with a thin layer of PDMS (polydimethylsiloxane), which serves as the stationary phase for the gas-chromatography.

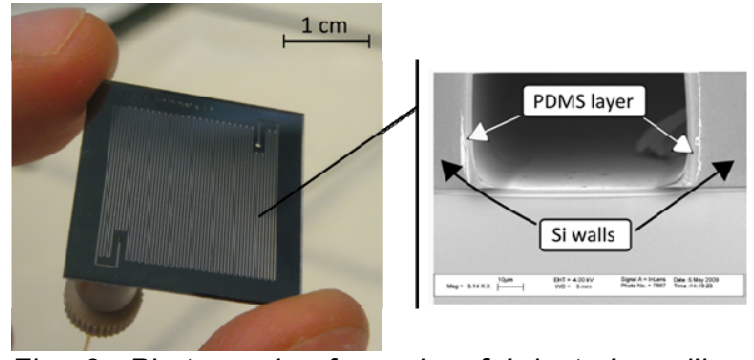

Fig. 2: Photograph of a micro-fabricated capillary (150 $\mu \mathrm{m}$ by $150 \mu \mathrm{m}$ cross section and $1 \mathrm{~m}$ length) 
PDMS has been chosen, since it is very similar to the DB-1 coating used in standard GC columns [8].

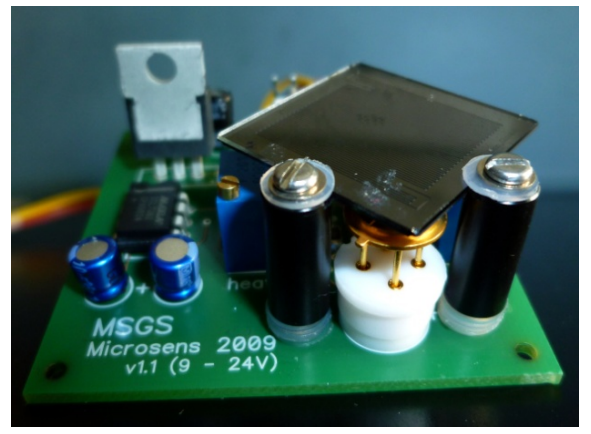

Figure 3: Photograph of the hybrid system including the $\mathrm{SnO}_{2}$ gas sensor, the sensor electronics and the micro-fabricated capillary.

Sensor and capillary are mounted onto the sensor electronics to obtain a compact sensing unit $(5 \mathrm{~cm} \times 5 \mathrm{~cm} \times 2 \mathrm{~cm})$, as Figure 3 shows. The MSGS gas sensor is hereby positioned at very close proximity to the capillary chip (< $1 \mathrm{~mm}$ ), and the sensor's $\mathrm{SnO}_{2}$ pixel is aligned to the capillary outlet. The sensor electronics drives the heating element and converts the sensor's resistance change into a voltage and amplifies the latter. The amplification allows measuring low VOC concentrations without sample pre-concentration.

The gaseous sample is injected into the capillary's continuous air flow via an electronically controlled three-way valve (ASCO) and the separated components are detected by the MSGS gas sensor at the capillary exit, as schematically shown in Figure 4. The flow through the capillary is driven by pressurized synthetic air at $10-45 \mathrm{kPa}$ above atmosphere. The injection time is set to $1 \mathrm{~s}$, which leads to an injected sample volume in $\mu \mathrm{l}-$ range. The focus of the experiments was to study the separation of the components, while less attention was paid to the limits of detection, since the MSGS has a known high sensitivity towards a wide range of VOC. Experiments were performed using different column designs and varying injection pressures, in order to evaluate the most suited set of parameters (column dimensions, injection time, pressure).

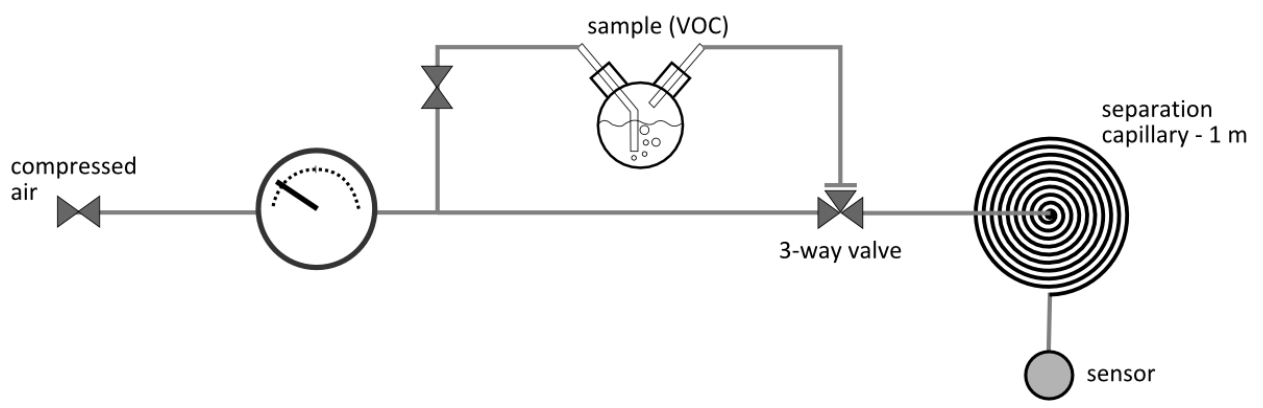

Fig. 4: Schematics of the gaseous pathways for the sample injection. The sample was introduced into the sample pathway by filling a tube with the gas-mixture of interest and plugging into the setup.

\section{Results and Discussion}

Since the MSGS sensors is highly responsive to solvent vapors, acetone, hexane and cyclohexane - which are solvents present in many types of glue - were used to evaluate the system. From measurements with standard GC-MS systems (using a DB-1 column) it is known, that these components arrive in the order 1. acetone, 2. hexane and 3. cyclohexane.

Figure 5 shows that a comparatively large and short capillary $(150 \mu \mathrm{m}$ by $150 \mu \mathrm{m}$ cross section and $1 \mathrm{~m}$ length) suffices to separately detect hexane and cyclohexane from a mixed sample. In order to increase the plate number $\mathrm{N}$ and thus the resolution of the column, variations in the column dimensions were introduced [9]. Increasing the column length while decreasing its cross section leads to a higher hydraulic resistance of the capillary as well as increased interaction between the molecules and the capillary walls and will allow to separately detect the VOCs from a mix of hexane and acetone (Figure 6), which would not be possible with the shorter capillary, since the peaks for acetone and hexane will overlap.

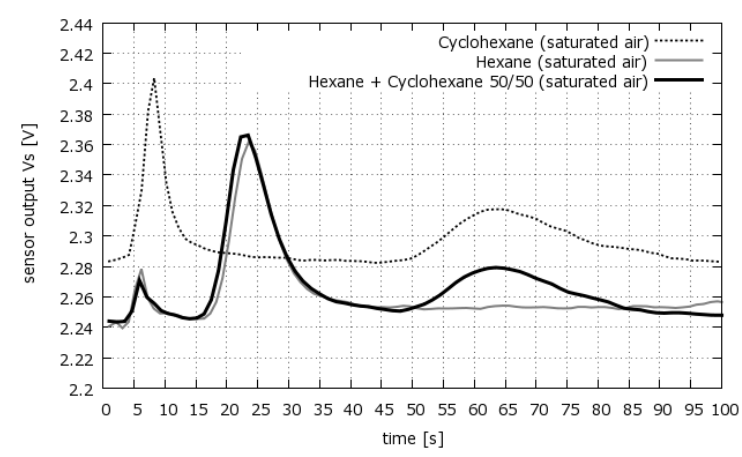

Figure 5: Recorded sensor signal for sample volumes of $1 \mu \mathrm{L}$ injected into a capillary of $150 \mu \mathrm{m}$ by $150 \mu \mathrm{m}$ cross section and $1 \mathrm{~m}$ length at a pressure of $15 \mathrm{kPa}$ (the first peak is a measurement artifact). Plate number for hexane: $N=6$. 
Increasing the hydraulic resistance of the column in order to increase the systems resolution of VOC will lead to longer measurement times, since the VOC take longer to transit the column. Therefore the column dimensions, system pressure and measurement time need to be adapted to the VOCs of interest.

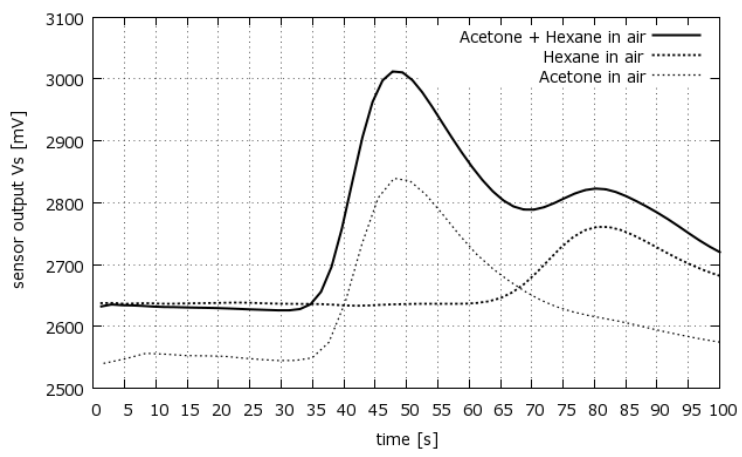

Fig. 6: Recorded sensor signal for a sample volume of $1 \mu \mathrm{L}$ injected into a capillary of $75 \mu \mathrm{m}$ by $150 \mu \mathrm{m}$ cross section and $2 \mathrm{~m}$ length at a pressure of $45 \mathrm{kPa}$. Plate number for hexane: $N=34$.

\section{Conclusion}

Combining a MSGS type $\mathrm{SnO}_{2}$ gas sensor with a micro-fabricated capillary allows the selective detection of multiple gaseous components in a gas sample using a single semiconductor gas sensor. The choice of capillary dimensions as well as system pressure makes it possible to tune the arrival time of the different gaseous components at the sensor. Thus the system can be adapted to a gas composition of interest, with the target VOC arriving at the measurement window. Since the separation step does not interfere with the sensor surface, the detection can fully profit from the high sensitivity of the $\mathrm{SnO}_{2}$ sensor, while the disadvantage of low selectivity has been reduced due to the sequential arrival of the components.

With the compact design of the detection module, a portable gas analysis system is being developed based on the approach presented here.

\section{Acknowledgements}

The authors would like to thank Dr. Arnaud Bertsch and Prof. Philippe Renaud (EPFL-IMTLMIS4) for fruitful discussions.

\section{References}

[1] R. Kumar, S. A. Imam, MASAUM Journal of Basic and Applied Sciences 1/3, 476 - 482 (2009)

[2] S. Zampolli, I. Elmi, J. Stürmann, S. Nicoletti, L. Dori, G.C. Cardinali, Sensors and Actuators B 105, 400-406 (2005); doi: 10.1016/j.snb.2004.06.036

[3] L. Berry, A. Hamwi, Sensors and Actuators B 150, 700-707 (2010); doi: 10.1016/j.snb.2010.08.017

[4] S. Reidy, G. Lambertus, J. Reece, R. Sacks, Anal. Chem. 78, 2623-2630 (2006); doi: 10.1021/ac051846u

[5] S.-I. Ohira, K. Toda, Analytica Chimica Acta 619, 143-156 (2008); doi:10.1016/j.aca.2008.05.010

[6] J.B. Sanchez, A. Schmitt, F. Berger, C. Mavon, Journal of Sensors 2010 (2010), doi:10.1155/2010/409687

[7] F. Berger, J.B. Sanchez, O. Heintz, Sensors and Actuators B 143, 152-157 (2009)

[8] http://www.chem.agilent.com/enUS/Products/columns-supplies/gc-gcmscolumns/jwdb-1/pages/default.aspx

[9] A.D. Radadia, A. Salehi-Khojin, R.I. Masel, M.A. Shannon, Sensors and Actuators B 150/1, 456464 (2010), doi: 10.1016/j.snb.2010.07.002 